(aryl ether) dendrons based on 3, 5-dihydroxybenzyl alcohol, developed by Fréchet, are amongst the most popular dendritic structures and have been widely used in organometallic catalysis, usually after metal functionalization at the core or focal point. The conformation adopted by the dendritic arms of these catalysts in solution is important because determines the nanoenvironment and accessibility of the metal centers. [2]

In our communication novel palladium (II) complexes with bis (pyrazol-1-yl) methane ligands at the focal point, of generations G0 to G3 poly (aryl ether) Fréchet-type dendrons are reported. The molecular structures of the metallodendrimer series G0-, G1-, and G2-[(dend) $\mathrm{CH}(3,5-$ $\left.\mathrm{Me}_{2} \mathrm{pz}\right)_{2}\left(\mathrm{PdCl}_{2}\right)$ ] have been determined by X-ray diffraction methods. The three structures show a similar three-dimensional organization of the metal complex, which is progressively engulfed by the branches with increasing dendrimer generation. Several interesting features are discussed and some new structural parameters to identify their configurations are defined. The higher generation (G2) is, to the best of our knowledge, the first transition-metal dendrimer $\mathbf{G} 2$ to be crystallographically characterized so far.

Details of the crystal structure based in weak hydrogen bonding interactions with the solvent and $\pi-\pi$ stacking are also examined.

[1] Sánchez-Méndez, A.; Benito, J. M.; de Jesús, E. ; de la Mata, F. J.; Flores, J. C.; Gómez, R.; Gómez-Sal, P. Dalton Trans. 2006, 5379-5389.

[2]a) Dendrimer Catalysis; Gade,L. H. Ed.; Springer: Berlin, 2006.

b) Andrés, R.; de Jesús, E.;Flores, J. C. New J. Chem. 2007

\section{MS15 P09}

Structural features of some organotin(IV) complexes of ONO donor Schiff bases Semra Ide ${ }^{a}$,Nilgün Ancin, Hasan Malkaş ${ }^{\mathrm{a}}$, Selma Gül Öztaş ${ }^{\mathrm{b}}{ }^{\mathrm{a}}$ Hacettepe University, Department of Physics Engineering, 06800 BeytepeAnkara,Turkey ${ }^{\mathrm{b}}$ Ankara University, Department of Chemistry, 06100 Besevler-Ankara, Turkey. E-mail: side@hacettepe.edu.tr

Keywords: Diorganotin(IV) complexes; Tridentate Schiff base; Crystal structure.

The Schiff bases of salicylaldehyde with aminopyridines are a well-known class of predominantly thermochromic compounds which have attracted a lot of interest from chemists for a long time [1]. Increasing attention has also been devoted to Schiff base complexes of organotin(IV) moieties in view of their potential applications in medicinal chemistry and biotechnology [2]. In this work, [N- (3-hydroxypyridine-2-yl) $-3, \quad 5-$ dichlorosalicylideneiminato] dimethyltin (IV) was characterized by single crystal x-ray diffraction method and a coordination geometry that is nearly half-way between trigonal-bipyramidal and square pyramidal arrangement was found. Unit cell parameters are: $\mathrm{a}=$ 9.601(1), b= 15.861(3), $c=10.98(1) \AA, B=113.83(2)^{\circ}$, $\mathrm{V}=1529.5(2) \AA^{3}$, Crystal system is monoclinic. The structure was solved by direct methods and refined by least squares on $\mathrm{F}^{2}{ }_{\text {obs }}$ by using SHELXL-97.The structural results were compared with its analogs in our previous studies [3,4]. It is found that the electronegativity of substituents influenced to the $\mathrm{C}=\mathrm{N}, \mathrm{Sn}-\mathrm{O}$ and $\mathrm{Sn}-\mathrm{N}$ bond lengths.

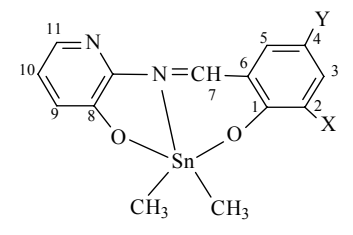

\begin{tabular}{|c|c|c|}
\hline & $\mathrm{X}$ & $\mathrm{Y}$ \\
\hline (1) & $\mathrm{H}$ & $\mathrm{H}$ \\
\hline (2) & $\mathrm{H}$ & $\mathrm{OH}$ \\
\hline (3) & $\mathrm{H}$ & $\mathrm{Br}$ \\
\hline (4) & $\mathrm{H}$ & $\mathrm{Cl}$ \\
\hline (5) & $\mathrm{Cl}$ & $\mathrm{Cl}$ \\
\hline
\end{tabular}

[1] Hadjoudis, E. Tautomerism by Hydrogen Transfer in Anil, Aci-Nitro and Related Compounds. In photochromism, H. Dürr, H. Bouas-Laurent, Eds.; Studies in Organic Chemistry 40; Elsevier science publishers, Amsterdam, 1990, 685.

[2] Gielen, M. Metal-based drugs. 1994, 1, 213.

[3]Öztaş, S.G.; Şahin, E.; Ancın, N.; Ide,S.; Tüzün, M. Z. Kristallogr. 2003, 218, 492.

[4]. Öztaş, S.G.; Şahin, E.; Ancın, N.; Ide,S.; Tüzün, Journal of Molecular Structure 2004, 705, 107.

\section{MS15 P10}

Crystal structure of Hexa- $\mu_{2}$-chloro- $\mu_{4}$-oxo-tetrakis(3,5-dimethylpyrazole)copper(II) Željko K. Jaćimović, ${ }^{a}$ Zoran D. Tomić ${ }^{\mathrm{b}}$ and Vukadin M. Leovac ${ }^{\mathrm{c}}{ }^{a}$ Faculty of Metallurgy and Technology, University of Montenegro, 81000 Podgorica, Montenegro, 'Vinca' Institute of Nuclear Sciences, Laboratory of Theoretical Physics and Condensed Matter Physics, 1001 Belgrade, Serbia. ${ }^{c}$ Institute of Chemistry, Faculty of Sciences, University of Novi Sad, Trg Dositeja Obradovica 3, 21000 Novi Sad, Serbia,

E-mail: zeljkoj@cg.ac.yu

Keywords Synthesis, Cu crystal structure, pyrazole based ligand

We report the synthesis, and structural characterization,of a novel tetranuclear copper(II) complex Cu4OX6L4 where $\mathrm{L}=3,5$-dimethylpyrazole.

Synthesis 3,5 -dimethylpyrazole-1-carboxamide $\quad(0,14 \mathrm{~g}$, $1 \mathrm{mmol})$ were dissolved in ethanol $\left(5 \mathrm{~cm}^{3}\right)$ and added to the hot solution of $\mathrm{CuCl}_{2} \cdot 2 \mathrm{H}_{2} \mathrm{O}(0,17 \mathrm{~g}, 1 \mathrm{mmol})$ in ethanol $\left(7 \mathrm{~cm}^{3}\right)$. Green crystals were obtained after one week. Four copper atoms (separated by the 3.070 (2)3.198 (3) $\AA$ ) encapsulate central $\mathrm{O}$ atom in a distorted tetrahedral arrangement, with the $\mathrm{Cu}-\mathrm{O}$ bond lengths of 1.903 (6)-1.914 (6) $\AA$, and the $\mathrm{Cu}-\mathrm{O}-\mathrm{Cu}$ angles of 107.3 (3)-114.3 (3) Between each pair of copper atoms, there is a bridging chlorine atom with a $\mathrm{Cu}-\mathrm{Cl}$ distances of 2,340(4) - 2,509(3) $\AA$. Closer inspection of the $\mathrm{Cu}-\mathrm{Cl}$ distances reveal grouping of values around every copper atom in a two 'short' and one 'long' distances.Average values are 2.375 and $2.459 \AA$ for 8 short and 6 long $\mathrm{Cu}-$ $\mathrm{Cl}$ distances respectively. Copper coordination sphere is completed by the 3,5-dimethylpyrazole ligand with $\mathrm{Cu}-$ $\mathrm{N}$ distances of 1,952(7) - 1,957(9) $\AA$. Coordination polyhedron can be described as a slightly distorted trigonal bipyramid where three chlorine atoms lie in the equatorial positions while the central oxygen and the 'pyridine' nitrogen from pyrazolyl ligand are placed at the axial sites. 